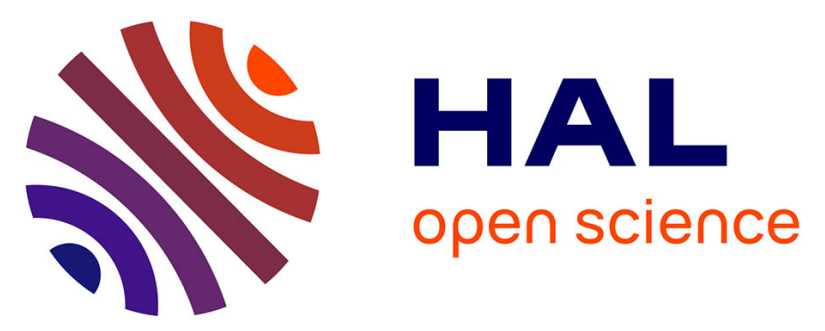

\title{
Is There a Benefit of Addition Docetaxel, Abiraterone, Celecoxib, or Zoledronic Acid in Initial Treatments for Patients Older Than 70 Years With Hormone-sensitive Advanced Prostate Cancer? A Meta-analysis
}

Thierry Landre, Gaetan Des Guetz, Kader Chouahnia, Virginie Fossey-Diaz, Cherifa Taleb, Stephane Culine

\section{To cite this version:}

Thierry Landre, Gaetan Des Guetz, Kader Chouahnia, Virginie Fossey-Diaz, Cherifa Taleb, et al.. Is There a Benefit of Addition Docetaxel, Abiraterone, Celecoxib, or Zoledronic Acid in Initial Treatments for Patients Older Than 70 Years With Hormone-sensitive Advanced Prostate Cancer? A Metaanalysis. Clinical Genitourinary Cancer, 2019, 17, pp.e806 - e813. 10.1016/j.clgc.2019.05.001 . hal03488039

\author{
HAL Id: hal-03488039 \\ https://hal.science/hal-03488039
}

Submitted on 20 Dec 2021

HAL is a multi-disciplinary open access archive for the deposit and dissemination of scientific research documents, whether they are published or not. The documents may come from teaching and research institutions in France or abroad, or from public or private research centers.
L'archive ouverte pluridisciplinaire HAL, est destinée au dépôt et à la diffusion de documents scientifiques de niveau recherche, publiés ou non, émanant des établissements d'enseignement et de recherche français ou étrangers, des laboratoires publics ou privés.

\section{(ㄷ)(1) $\$$}

Distributed under a Creative Commons Attribution - NonCommerciall 4.0 International 


\section{Is there a benefit of addition docetaxel, abiraterone, celecoxib or zoledronic acid in initial treatments for patients older than 70 years with hormone sensitive advanced prostate cancer? A Meta-analysis.}

Authors: Thierry Landre (1,4), Gaetan Des Guetz (2), Kader Chouahnia (2), Virginie FosseyDiaz (3), Cherifa Taleb (4), Stephane Culine (5)

(1) Geriatric Oncology Coordination Unit - UCOG 93, APHP, René Muret Hospital, HUPSSD - Université Paris 13, Sevran, France.

(2) Oncology Department, CH Delafontaine, Université de Limoges, St Denis, France

(3) Geriatric Department, AP-HP, Bretonneau Hospital, 23 Rue Joseph de Maistre, F-75018, Paris, France.

(4) Geriatric Department, AP-HP, René Muret Hospital, Avenue Schaeffner, F-93270, Sevran, France.

(5) Department of Medical Oncology, AP-HP, Saint-Louis Hospital, 1 Avenue Claude Vellefaux, F-75010, Paris, France; Paris Diderot University, 5 Rue Thomas Mann, F-75013, Paris, France.

Keywords: Elderly, Metastatic Prostate Cancer, First Line, Abiraterone, Docetaxel, Celecoxib, Meta-Analysis

Conflict-of-interest statement: The authors declare no conflict of interest

Author contributions: All authors contributed to the design of the article and review of the literature; Landre T edited the manuscript; all authors participated in the critical revision and approval of the final version of the article.

Corresponding author: Dr Thierry Landre

Unité de coordination en oncogériatrie-UCOG93

Hôpital René Muret- APHP

Avenue du Dr Schaeffner 93270 Sevran

thierry.landre@aphp.fr 


\section{Is there a benefit of addition docetaxel, abiraterone, celecoxib or zoledronic acid in initial treatments for patients older than 70 years with hormone sensitive advanced prostate cancer? A Meta-analysis.}

Background: Results from large randomized controlled trials combining docetaxel, abiraterone, celecoxib or bisphosphonates with androgen deprivation therapy (ADT) in hormone-sensitive prostate cancer have emerged. However, in our knowledge, few data are available in patients older than 70 years. Therefore, we undertook a meta-analysis of all published phase III studies.

Methods: We performed a PubMed search using key-words: "hormone sensitive prostate cancer", "phase III studies", “docetaxel”, "abiraterone”, “celecoxib”, "biphosphonates". We also screened ASCO and ESMO proceedings. Combination therapies were compared with ADT alone. The efficacy outcomes were overall survival (OS) and progression free survival (PFS). Hazard ratios (HRs) with their $95 \%$ confidence interval (CI) were collected from the studies and pooled. A hazard ratio of less than 1.00 favored the combination group.

Results: This meta-analysis included eight studies: three assess docetaxel (CHAARTED, STAMPEDE arm E and C), two others assess abiraterone (LATITUDE, and STAMPEDE arm G); two others assess celecoxib (STAMPEDE arm D and F) and the last one assesses zoledronic acid alone (STAMPEDE arm B). Our meta-analysis included 2264 patients (86\% with metastases). Concerning age, we chose a cut-off of 70 years, corresponding to the available data for each study. The performance index (PS) was 0-1 for about $90 \%$ of patients. Overall, in patients $>70$ years old, the addition of docetaxel statistically improved PFS (HR = 0.51; CI: $0.42-0.61)$ but not OS (HR $=0.86$; CI: $0.69-1.07)$. The addition of abiraterone to ADT also statistically improved PFS (HR $=0.49$; CI: 0.37-0.64) but not OS (HR =0.85; CI: 0.67-1.08), as well as the addition of celecoxib (HR $=0.67$; CI: $0.53-0.85$ and $\mathrm{HR}=0.95$; CI: $0.73-1.25$, respectively). The addition of zoledronic acid did not improved PFS or OS (HR = 0.78; CI: 0.61-1.00 and HR = 0.99; CI: 0.71-1.38, respectively).

Conclusions: The addition of docetaxel, abiraterone, or celecoxib to ADT significantly increased PFS in older with hormone-sensitive advanced prostate cancer. However the benefit in OS is not statistically significant. Further studies are needed to define the best first-line strategy in this subgroup. 


\section{Introduction}

Management of older patients with prostate cancer is a growing clinical dilemma. Prostate cancer primarily affects older patients and the median age at death by prostate cancer is 80 years (1). Life expectancy is rapidly improving, however older patients are often excluded from clinical trials (2), (3). Indeed, despite that almost a quarter of men diagnosed with prostate cancer are 75 years or older (4), no prospective study has been devoted to this subgroup.

For several decades, the standard-of-care (SOC) for patients with metastatic prostate cancer has been long-term androgen deprivation therapy (ADT) alone. Numerous randomized controlled trials (RCTs) have evaluated, or are currently evaluating, the addition of other therapies to ADT in men with advanced hormone-sensitive prostate cancer. In the past few years combined systemic treatments demonstrated a survival benefit: docetaxel plus prednisolone/prednisone and, most recently, abiraterone acetate plus prednisolone/prednisone in combination with ADT have shown a clinical benefit $(5,6)$. However, to our knowledge, few data are available for older patients.

To assess the optimal treatments in older, a meta-analysis of the literature was performed based on aggregate data from all available studies. 


\section{Methods}

\section{Publication selection}

We performed a meta-analysis according to a predefined written protocol. Eligible studies included patients more than 70 years old with hormone-sensitive advanced prostate cancer having a first-line treatment either with ADT or addition of other therapies to ADT.

Only randomized phase III controlled trials comparing these two treatment modalities were included. They compared benefits and risks of both treatment modalities concerning OS, PFS and toxicities. Publications included in this meta-analysis were identified by an electronic PubMed search updated on January 2018 using the following key-words: "Hormone-sensitive, prostate cancer, elderly, ADT, docetaxel, abiraterone, zoledronic acid, celecoxib, phase III, survival, meta-analysis". Concerning age, we chose a cut-off of 70 years, corresponding to the available data for each study.

An EMBASE query did not bring additional references. We did not find a systematic review on this topic in the Cochrane database. We tried to obtain additional references by crosschecking the available publications. We also searched for abstracts in the proceedings of American Society of Clinical Oncology (ASCO) (2014-2018) and European Society of Medical Oncology (ESMO) (2014-2018) conferences. As scheduled in a written protocol, each article was carefully read by three reviewers (GDG, TL and SC). GDG, KC, CT, VFD and SC putting the emphasis on oncological and geriatric clinical aspects and TL and CT putting the emphasis on methodological aspects. The reviewers had to fill in separately a predefined form. Disagreements were resolved by discussion between all authors of this metaanalysis. 


\section{Statistical analysis}

In each study, the efficacy of treatment in the older population was considered significant when the $\mathrm{p}$ value for the statistical test comparing survival distributions was below 0.05 (twotailed test). For each study, the hazard ratio (HR) was estimated by a method depending on the data provided in the publication. The simplest method consisted of the direct collection of HRs with their $95 \%$ confidence intervals (CIs) when mentioned in the original publication. If not available, we looked at the total number of events (deaths, progression and side effects) and at the numbers of patients at risk in each group to calculate the RR. When data were only available as graphical survival plots, the calculations were made only if the number of steps on the curves equalled the number of events given in the publication, assuming that the rate of censored patients was constant during the study follow-up. By convention, in each study, we chose as reference the ADT and HRs lower than 1 meant that survival was better among patients with the combined treatment or that side effects were less frequent with the addition of other therapies to ADT. About the results of this meta-analysis, $\mathrm{p}$ values for pooled data lower than 0.05 were considered as statistically significant. We calculated a HR estimate and its $95 \%$ CI by using a fixed-effect model (Mantel Haenszel) due to the absence of heterogeneity between studies. In the rare cases of significant heterogeneity between studies, we used a random effect model. The statistical calculations used the Review Manager 5.3 statistical package (Cochrane Collaboration Software). TL performed the statistical analysis. 


\section{Results}

Searches undertaken for this study identified 11 trials that were eligible for inclusion in the meta-analysis (Figures 1 and 2). Concerning zoledronic acid, the studies by Smith et al. (7), and by Kamba et al. (8) were excluded since results stratified by age categories were not available. Concerning docetaxel, the study by Gravis et al. (9) was excluded because all patients of the study were $<70$ years old.

Finally, our meta-analysis included eight studies: Three assess the addition of docetaxel : CHAARTED by Sweeney et al.(10,11) and STAMPEDE (arm E and arm C), by James et al. (12); two others assess the addition of abiraterone: LATITUDE by Fizazi et al. (13), and STAMPEDE (arm G) by James et al. (14) two others assess the addition of celecoxib : STAMPEDE (arm D and arm F) by Mason et al. $(15,16)$; and the last one assess the addition of zoledronic acid alone : STAMPEDE (arm B) by James et al. (12).

Overall, 2264 elderly patients were included in the eight trials in the meta-analysis, 439 (19\%) assigned to docetaxel and ADT, $445(19.5 \%)$ assigned to abiraterone and ADT, $172(7.5 \%)$ assigned to zoledronic acid and ADT, 180 (8\%) assigned to celecoxib and ADT and 1028 (46\%) assigned to ADT alone (Table 1). The main characteristics of the 2264 patients are described in Table 1. Patients were enrolled between October 2005 and March 2013. Median age was 64-68 years. Two trials (CHAARTED and LATITUDE) enrolled only metastatic patients; in the STAMPEDE trials, metastatic patients were $61 \%$ of the total study population (except for Arm G with 52\% of the total population). Overall, there were 1941 metastatic elderly patients which represent $86 \%$. The performance index (PS) was $0-1$ for about $90 \%$ of patients. 


\section{$\underline{\text { Overall Survival }}$}

In the older population (> 70 years), Overall Survival (OS) did not differ significantly between patients in the ADT + docetaxel group and those in the ADT group: hazard ratio $(\mathrm{HR}=0 \cdot 86 ; 95 \% \mathrm{CI} 0 \cdot 69-1 \cdot 07 ; \mathrm{p}=0 \cdot 18)$. However, a significant gain in survival was observed in the CHAARTED study.

The clinical benefit was not statistically significant for OS results with ADT + abiraterone group : hazard ratio $(\mathrm{HR}=0 \cdot 85 ; 95 \%$ CI $0 \cdot 67-1 \cdot 08 ; \mathrm{p}=0 \cdot 19)$, ADT + celecoxib group : hazard ratio $(\mathrm{HR}=0 \cdot 95 ; 95 \% \mathrm{CI} 0 \cdot 73-1 \cdot 25 ; \mathrm{p}=0 \cdot 74)$ and $\mathrm{ADT}+$ zoledronic acid group $:$ hazard ratio $(\mathrm{HR}=0 \cdot 99 ; 95 \%$ CI $0 \cdot 71-1 \cdot 38 ; \mathrm{p}=0 \cdot 95)$ (figure 3$)$. An independent analysis was also performed with abiraterone and docetaxel studies on the one hand and studies on zoledronic acid and celecoxib on the other (figure 4). A non-statistically significant survival benefit was observed in the abiraterone / or docetaxel group $(\mathrm{HR}=0.86$; 95\% CI 0.73-1.01) compared with the zoledronic acid / or celecoxib group $(\mathrm{HR}=0.97 ; 95 \% \mathrm{CI} 0.78-1.20)$.

In the younger population ( $<70$ years), (figure 5) OS differ significantly between patients in the ADT + docetaxel or ADT + abiraterone groups and those in the ADT group: $(\mathrm{HR}=0 \cdot 73$; 95\% CI 0.64-0.83; $<<0 \cdot 0001)$ and $(\mathrm{HR}=0 \cdot 52 ; 95 \%$ CI 0.43-0.63; $<<0 \cdot 0001)$ respectively.

\section{$\underline{\text { Progression Free Survival: }}$}

Overall, the addition of docetaxel to ADT statistically improved PFS (HR $=0.51$; CI: $0.42-$ 0.61 ) in older patients. The addition of abiraterone also statistically improved PFS (HR $=0.49$; CI: $0.37-0.64)$ as well as the addition of celecoxib (HR $=0.67$; CI: $0.53-0.85)$. The addition of zoledronic acid to ADT did not statistically improved PFS (HR = 0.78; CI: 0.61-1) (figure $6)$. 


\section{Discussion}

This is the first meta-analysis to comprehensively assess the effects of all the systemic treatments for Hormone Sensitive Prostate Cancer (HSPC) recently tested in RCTs in older patients. The age group selected for this meta-analysis was the age group 70 and over. It accounts for about $20 \%$ in CHAARTED to $40 \%$ in LATITUDE of patients included in phase III studies. We do not have any data available for the over 75 age group. This cutoff would have been more relevant and more representative of the older population.

Our meta-analysis fails to show a global impact of two drugs treatments on OS in older patients with HSPC while the interest of these combinations is demonstrated in younger patients. However, several biases should be considered. One of limitations is the lack of power of the studies (number of older patients included too small to show a real difference) as well as the fact of not knowing the cause of the deaths of the patients. Finally, the fact that the population of STAMPEDE is heterogeneous (with an inclusion of metastatic and nonmetastatic patients) is a major bias.

However, the results of our meta-analysis in older patients show a benefit of PFS for the addition of docetaxel, celecoxib or abiraterone. A significant benefit is also obtained in OS but only for the addition of docetaxel thanks to the results of the CHAARTED study. We therefore need more information on whether the results of chemohormonal therapy can be extrapolated to older patients. It is likely that patients with metastatic prostate cancer, especially those with high-volume disease, who are fit to receive docetaxel in addition to ADT may benefit from such a regimen (17). However the risk/benefit balance should be discussed carefully with each patient. Docetaxel may be associated with neutropenic fever, 
peripheral neuropathy, and treatment related deaths. AEs grades 3 or 4 were common with docetaxel, mostly as a result of hematologic toxicities (18). The risk of toxic death was significantly increased in older patients, which might be expected given the possibility of lessfit patients, decreased overall life expectancy and inability to tolerate aggressive chemotherapy regimens $(19,20)(21)$.

In the STAMPEDE study, the low number of older patients included may explain the lack of statistical benefit. There is only a difference of 8 deaths between the experimental arm and the control arm in this population. Co-morbidities should also be considered because older patients may die from causes other than cancer (14). For unfit older patients or older patients with low volume the use of abiraterone can be discussed and deserves to be studied (22). The disadvantages of abiraterone are high cost, long treatment time and potential compliance problems. However, abiraterone is generally considered to be a better tolerated oral option. In terms of tolerance, the use of abiraterone may increase the risk of cardiac disorders, hypertension, hypokalemia and AST-AST elevation, but abiraterone has recently been shown to improve the quality of life of patients (23).

The International Society of Geriatric Oncology (SIOG) states that all patients above the age of 70 years with cancer should undergo a three step procedure for a geriatric assessment (2). It is important to note that in these studies there was no Comprehensive Geriatric Assessment (CGA), although it is recommended. Patient goals of care, social supports, consideration of comorbidities, and access to medical care are important determinants when choosing the optimal treatment of an individual. Patients with cancer treated in clinical trials differ from patients who were not because the former are generally younger and have less comorbidity, 
which may lead to differential outcomes (24). It is essential to take into account life expectancy outside the cancer, comorbidities, malnutrition and also frailty.

The HSPC first-line treatment strategy is thus more complex for older patients. For the whole population the optimal treatment of HSPC in the front line is controversial. The first metaanalysis showed improved survival for men with metastatic hormone-naive prostate cancer when abiraterone or docetaxel, but not zoledronic acid, were added to ADT (25) (26) (27). Trial evidence also suggests a benefit of combining celecoxib with zoledronic acid and ADT (15). More recently, another meta-analysis was published to establish the optimal initial treatment (28). Results suggest that abiraterone has the highest probability of being the most effective treatment both for OS (94\% probability) and FFS (100\% probability). Docetaxel was the second-best treatment for overall survival (35\% probability). For older patients, our metaanalysis also shows the benefit of adding abiraterone or docetaxel, although the results are less convincing than in younger patients.

New strategies actually emerge in the management of metastatic hormone-sensitive prostate cancers: Randomised data on docetaxel with or without abiraterone will emerge from a subset the PEACE-1 trial, as will non-randomised, time-stratified data on abiraterone with or without docetaxel. Recently, phase 3 ARCHES trial shows enzalutamide significantly improved radiographic Progression Free Survival in men with metastatic hormone-sensitive prostate cancer. Patients had a median age of 70 years (29). Similarly comparative data will also emerge for apalutamide, another AR-targeted therapy, from the TITAN trial. The impact of these new strategies will also need to be assessed in older patients. 


\section{Conclusion}

In this meta-analysis, the addition of docetaxel or abiraterone to ADT does not significantly improve the overall survival of patients over 70 years of age with hormone-sensitive advanced prostate cancer. However, there are probably subgroups of patients may benefit from a combination of docetaxel or abiraterone. Specifically designed geriatric studies are needed to further clarify the optimal therapeutic strategies in this population. 


\section{References}

1. Prostate Cancer - Cancer Stat Facts [Internet]. SEER. [cité 9 janv 2019]. Disponible sur: https://seer.cancer.gov/statfacts/html/prost.html

2. Droz J-P, Albrand G, Gillessen S, Hughes S, Mottet N, Oudard S, et al. Management of Prostate Cancer in Elderly Patients: Recommendations of a Task Force of the International Society of Geriatric Oncology. Eur Urol. oct 2017;72(4):521-31.

3. Grummet JP, Plass K, N'Dow J. Prostate Cancer Management in an Ageing Population. Eur Urol. oct 2017;72(4):532-3.

4. Heinzer H, Steuber T. Prostate cancer in the elderly. Urol Oncol. déc 2009;27(6):668-72.

5. Feyerabend S, Saad F, Li T, Ito T, Diels J, Van Sanden S, et al. Survival benefit, disease progression and quality-of-life outcomes of abiraterone acetate plus prednisone versus docetaxel in metastatic hormone-sensitive prostate cancer: A network meta-analysis. Eur J Cancer Oxf Engl 1990. 12 sept 2018;103:78-87.

6. McNamara M, Sweeney C, Antonarakis ES, Armstrong AJ. The evolving landscape of metastatic hormone-sensitive prostate cancer: a critical review of the evidence for adding docetaxel or abiraterone to androgen deprivation. Prostate Cancer Prostatic Dis. sept 2018;21(3):306-18.

7. Smith MR, Halabi S, Ryan CJ, Hussain A, Vogelzang N, Stadler W, et al. Randomized controlled trial of early zoledronic acid in men with castration-sensitive prostate cancer and bone metastases: results of CALGB 90202 (alliance). J Clin Oncol Off J Am Soc Clin Oncol. 10 avr 2014;32(11):1143-50.

8. Kamba T, Kamoto T, Maruo S, Kikuchi T, Shimizu Y, Namiki S, et al. A phase III multicenter, randomized, controlled study of combined androgen blockade with versus without zoledronic acid in prostate cancer patients with metastatic bone disease: results of the ZAPCA trial. Int J Clin Oncol. févr 2017;22(1):166-73.

9. Gravis G, Fizazi K, Joly F, Oudard S, Priou F, Esterni B, et al. Androgen-deprivation therapy alone or with docetaxel in non-castrate metastatic prostate cancer (GETUG-AFU 15): a randomised, open-label, phase 3 trial. Lancet Oncol. févr 2013;14(2):149-58.

10. Sweeney CJ, Chen Y-H, Carducci M, Liu G, Jarrard DF, Eisenberger M, et al. Chemohormonal Therapy in Metastatic Hormone-Sensitive Prostate Cancer. N Engl J Med. 20 août 2015;373(8):737-46.

11. Kyriakopoulos CE, Chen Y-H, Carducci MA, Liu G, Jarrard DF, Hahn NM, et al. Chemohormonal Therapy in Metastatic Hormone-Sensitive Prostate Cancer: Long-Term Survival Analysis of the Randomized Phase III E3805 CHAARTED Trial. J Clin Oncol Off J Am Soc Clin Oncol. 10 avr 2018;36(11):1080-7.

12. James ND, Sydes MR, Clarke NW, Mason MD, Dearnaley DP, Spears MR, et al. Addition of docetaxel, zoledronic acid, or both to first-line long-term hormone therapy in prostate cancer (STAMPEDE): survival results from an adaptive, multiarm, multistage, platform randomised controlled trial. Lancet Lond Engl. 19 mars 2016;387(10024):1163-77. 
13. Fizazi K, Tran N, Fein L, Matsubara N, Rodriguez-Antolin A, Alekseev BY, et al. Abiraterone plus Prednisone in Metastatic, Castration-Sensitive Prostate Cancer. N Engl J Med. 27 2017;377(4):352-60.

14. James ND, de Bono JS, Spears MR, Clarke NW, Mason MD, Dearnaley DP, et al. Abiraterone for Prostate Cancer Not Previously Treated with Hormone Therapy. N Engl J Med. 27 2017;377(4):338-51.

15. Mason MD, Clarke NW, James ND, Dearnaley DP, Spears MR, Ritchie AWS, et al. Adding Celecoxib With or Without Zoledronic Acid for Hormone-Naïve Prostate Cancer: Long-Term Survival Results From an Adaptive, Multiarm, Multistage, Platform, Randomized Controlled Trial. J Clin Oncol Off J Am Soc Clin Oncol. 10 mai 2017;35(14):1530-41.

16. James ND, Sydes MR, Mason MD, Clarke NW, Anderson J, Dearnaley DP, et al. Celecoxib plus hormone therapy versus hormone therapy alone for hormone-sensitive prostate cancer: first results from the STAMPEDE multiarm, multistage, randomised controlled trial. Lancet Oncol. mai 2012;13(5):549-58.

17. Gravis G, Boher J-M, Chen Y-H, Liu G, Fizazi K, Carducci MA, et al. Burden of Metastatic Castrate Naive Prostate Cancer Patients, to Identify Men More Likely to Benefit from Early Docetaxel: Further Analyses of CHAARTED and GETUG-AFU15 Studies. Eur Urol. juin 2018;73(6):847-55.

18. Buttigliero C, Tucci M, Vignani F, Di Stefano RF, Leone G, Zichi C, et al. ChemotherapyInduced Neutropenia and Outcome in Patients With Metastatic Castration-Resistant Prostate Cancer Treated With First-Line Docetaxel. Clin Genitourin Cancer. août 2018;16(4):318-24.

19. Mohile SG, Dale W, Somerfield MR, Schonberg MA, Boyd CM, Burhenn PS, et al. Practical Assessment and Management of Vulnerabilities in Older Patients Receiving Chemotherapy: ASCO Guideline for Geriatric Oncology. J Clin Oncol Off J Am Soc Clin Oncol. 1 août 2018;36(22):2326-47.

20. Versteeg KS, Konings IR, Lagaay AM, van de Loosdrecht AA, Verheul HMW. Prediction of treatment-related toxicity and outcome with geriatric assessment in elderly patients with solid malignancies treated with chemotherapy: a systematic review. Ann Oncol Off J Eur Soc Med Oncol. oct 2014;25(10):1914-8.

21. Thompson AL, Sarmah P, Beresford MJ, Jefferies ER. Management of metastatic prostate cancer in the elderly: identifying fitness for chemotherapy in the post-STAMPEDE world. BJU Int. 2017;120(6):751-4.

22. Hoyle AP, Ali SA, James ND, Parker CC, Cook AD, Attard G, et al. LBA4Effects of abiraterone acetate plus prednisone/prednisolone in high and low risk metastatic hormone sensitive prostate cancer. Ann Oncol [Internet]. 1 oct 2018 [cité 25 janv 2019];29(suppl_8). Disponible sur: https://academic.oup.com/annonc/article/doi/10.1093/annonc/mdy424.033/5141727

23. Chi KN, Protheroe A, Rodríguez-Antolín A, Facchini G, Suttman H, Matsubara N, et al. Patientreported outcomes following abiraterone acetate plus prednisone added to androgen deprivation therapy in patients with newly diagnosed metastatic castration-naive prostate cancer (LATITUDE): an international, randomised phase 3 trial. Lancet Oncol. févr 2018;19(2):194206. 
24. Dunn C, Wilson A, Sitas F. Older cancer patients in cancer clinical trials are underrepresented. Systematic literature review of almost 5000 meta- and pooled analyses of phase III randomized trials of survival from breast, prostate and lung cancer. Cancer Epidemiol. 2017;51:113-7.

25. Rydzewska LHM, Burdett S, Vale CL, Clarke NW, Fizazi K, Kheoh T, et al. Adding abiraterone to androgen deprivation therapy in men with metastatic hormone-sensitive prostate cancer: A systematic review and meta-analysis. Eur J Cancer Oxf Engl 1990. 2017;84:88-101.

26. Vale CL, Burdett S, Rydzewska LHM, Albiges L, Clarke NW, Fisher D, et al. Addition of docetaxel or bisphosphonates to standard of care in men with localised or metastatic, hormonesensitive prostate cancer: a systematic review and meta-analyses of aggregate data. Lancet Oncol. févr 2016;17(2):243-56.

27. Sydes MR, Spears MR, Mason MD, Clarke NW, Dearnaley DP, de Bono JS, et al. Adding abiraterone or docetaxel to long-term hormone therapy for prostate cancer: directly randomised data from the STAMPEDE multi-arm, multi-stage platform protocol. Ann Oncol Off J Eur Soc Med Oncol. 26 févr 2018;

28. Vale CL, Fisher DJ, White IR, Carpenter JR, Burdett S, Clarke NW, et al. What is the optimal systemic treatment of men with metastatic, hormone-naive prostate cancer? A STOPCAP systematic review and network meta-analysis. Ann Oncol. 1 mai 2018;29(5):1249-57.

29. Armstrong AJ, Szmulewitz RZ, Petrylak DP, Villers A, Azad A, Alcaraz A, et al. Phase III study of androgen deprivation therapy (ADT) with enzalutamide (ENZA) or placebo (PBO) in metastatic hormone-sensitive prostate cancer (mHSPC): The ARCHES trial. J Clin Oncol. 26 févr 2019;37(7_suppl):687-687. 
PRISMA 2009 Flow Diagram (Fig. 1)

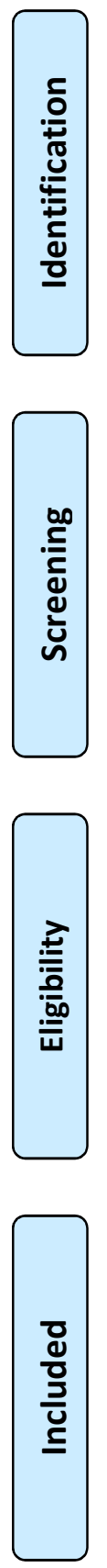

Records identified through database

searching

$(\mathrm{n}=1104)$
Additional records identified through other sources $(\mathrm{n}=212)$

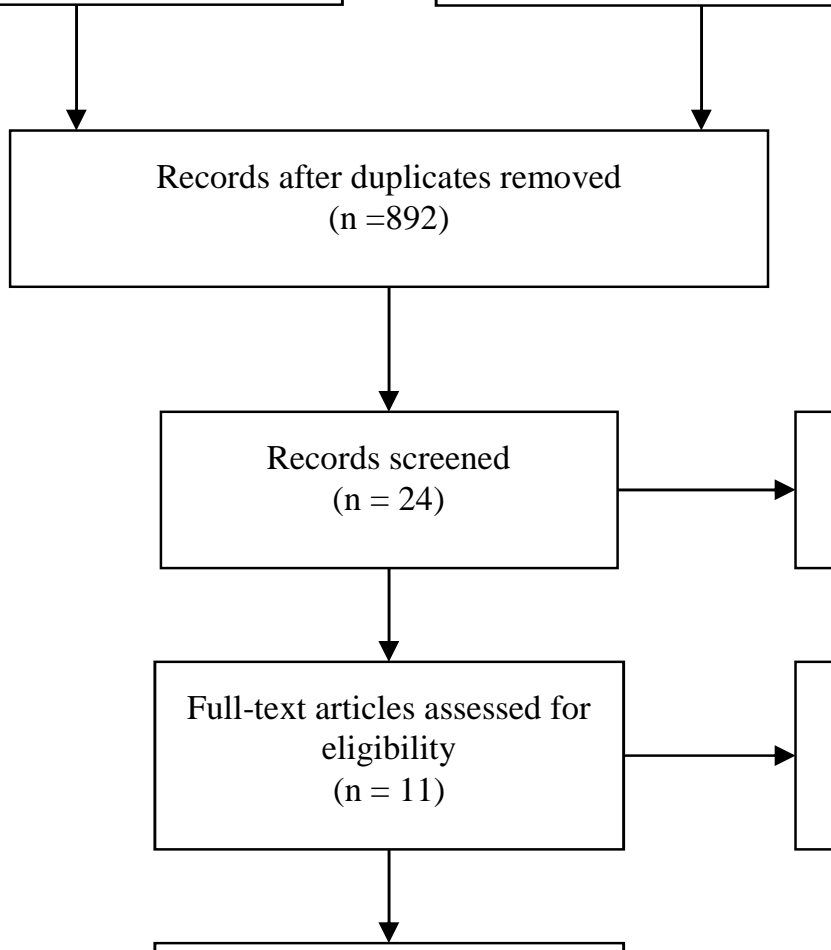

Full-text articles excluded, with reasons $(\mathrm{n}=3)$

Studies included in qualitative synthesis $(\mathrm{n}=8)$ quantitative synthesis (metaanalysis) $(\mathrm{n}=8)$ 
Fig. 2 Publication bias assessed by funnel plot

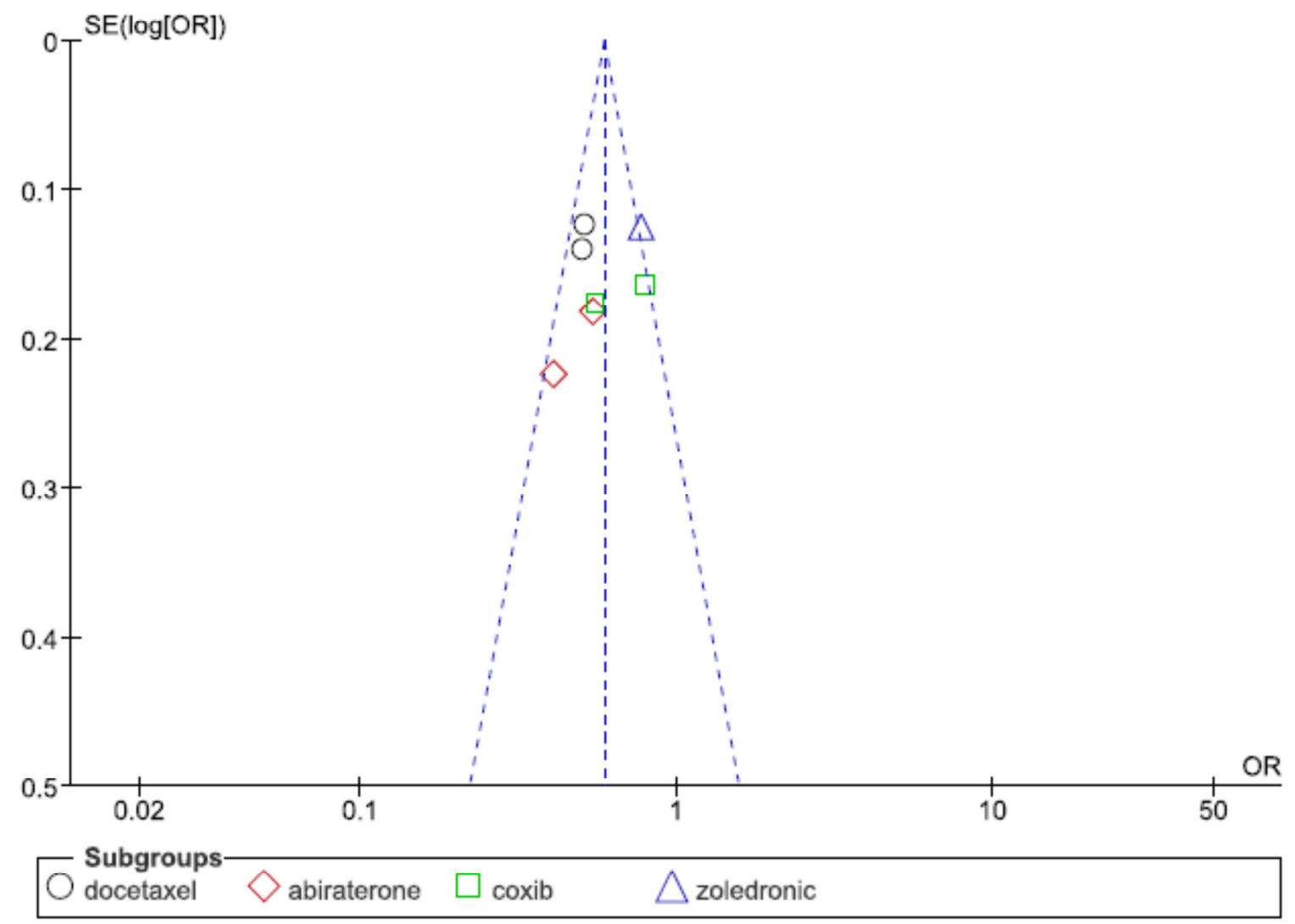


Table 1 Main characteristics of the studies included in the meta-analysis

\begin{tabular}{|c|c|c|c|c|}
\hline Trial & $\begin{array}{l}\text { Recruitment } \\
\text { period }\end{array}$ & Treatment & Younger $(\mathrm{N})<70$ & Older $(\mathrm{N})>70$ \\
\hline $\begin{array}{l}\text { CHAARTED } \\
\text { Sweeney } 2015(10)\end{array}$ & $\begin{array}{l}\text { July } 2006- \\
\text { Dec } 2012\end{array}$ & $\mathrm{ADT}+\mathrm{Doc}$ & 612 & $178(22 \%)$ \\
\hline $\begin{array}{l}\text { STAMPEDE } \\
\text { (Arms A vs C) } \\
\text { James } 2016(12)\end{array}$ & $\begin{array}{l}\text { Oct } 2005- \\
\text { March } 2013\end{array}$ & ADT + Doc & 1252 & $524(29 \%)$ \\
\hline $\begin{array}{l}\text { STAMPEDE } \\
\text { (Arms A vs E) } \\
\text { James } 2016(12)\end{array}$ & $\begin{array}{l}\text { Oct } 2005- \\
\text { March } 2013\end{array}$ & $\mathrm{ADT}+\mathrm{ZA}+\mathrm{Doc}$ & 1249 & $528(29 \%)$ \\
\hline $\begin{array}{l}\text { STAMPEDE } \\
\text { (Arms A vs G) } \\
\text { James } 2017 \text { (14) }\end{array}$ & $\begin{array}{l}\text { Nov 2011- } \\
\text { Jan } 2014\end{array}$ & $\mathrm{ADT}+\mathrm{AAP}$ & 1199 & $718(37 \%)$ \\
\hline $\begin{array}{l}\text { LATITUDE } \\
\text { Fizazi } 2017 \text { (13) }\end{array}$ & $\begin{array}{l}\text { Feb } 2013- \\
\text { Dec } 2014\end{array}$ & $\mathrm{ADT}+\mathrm{AAP}$ & 700 & $499(41 \%)$ \\
\hline $\begin{array}{l}\text { STAMPEDE } \\
\text { (Arms A vs B) } \\
\text { James } 2016(12)\end{array}$ & $\begin{array}{l}\text { Oct } 2005- \\
\text { March } 2013\end{array}$ & $\mathrm{ADT}+\mathrm{ZA}$ & 1254 & $523(29 \%)$ \\
\hline $\begin{array}{l}\text { STAMPEDE } \\
\text { (Arms A vs F) } \\
\text { Mason } 2017 \text { (15) }\end{array}$ & $\begin{array}{l}\text { Oct } 2005- \\
\text { April } 2011\end{array}$ & $\mathrm{ADT}+\mathrm{ZA}+\mathrm{Cel}$ & 661 & $272(29 \%)$ \\
\hline $\begin{array}{l}\text { STAMPEDE } \\
\text { (Arms A vs D) } \\
\text { Mason } 2017(15)\end{array}$ & $\begin{array}{l}\text { Oct } 2005- \\
\text { April } 2011\end{array}$ & ADT + Cel & 660 & $274(29 \%)$ \\
\hline
\end{tabular}

AAP= Abiraterone Acetate plus prednisone ; ADT= Androgen Deprivation Therapy ; Cel= celecoxib ; Doc $=$ docetaxel ; $\mathrm{ZA}=$ 


\begin{tabular}{|c|c|c|c|c|c|}
\hline Trial & Gleason $>$ or $=8$ & Treatment & PSA = median & $\begin{array}{l}\text { Age, median } \\
\text { (years) }\end{array}$ & $\begin{array}{l}\text { Age, range } \\
\text { (years) }\end{array}$ \\
\hline CHAARTED & $61 \%$ & ADT + Doc & 50 & 64 & $36-88$ \\
\hline $\begin{array}{l}\text { STAMPEDE } \\
\text { (Arms A vs C) }\end{array}$ & $72 \%$ & ADT + Doc & 70 & 65 & $40-81$ \\
\hline $\begin{array}{l}\text { STAMPEDE } \\
\text { (Arms A vs E) }\end{array}$ & $72 \%$ & $A D T+Z A+D o c$ & 63 & 66 & $42-84$ \\
\hline $\begin{array}{l}\text { STAMPEDE } \\
\text { (Arms A vs G) }\end{array}$ & $75 \%$ & ADT + AAP & 56 & 67 & $42-85$ \\
\hline LATITUDE & $98 \%$ & ADT + AAP & 23 & 68 & $38-89$ \\
\hline $\begin{array}{l}\text { STAMPEDE } \\
\text { (Arms A vs B) }\end{array}$ & $72 \%$ & $\mathrm{ADT}+\mathrm{ZA}$ & & 66 & $42-82$ \\
\hline $\begin{array}{l}\text { STAMPEDE } \\
\text { (Arms A vs F) }\end{array}$ & $65 \%$ & $\mathrm{ADT}+\mathrm{ZA}+\mathrm{Cel}$ & 57 & 65 & $37-94$ \\
\hline $\begin{array}{l}\text { STAMPEDE } \\
\text { (Arms A vs D) }\end{array}$ & $65 \%$ & ADT + Cel & 70 & 66 & $41-80$ \\
\hline
\end{tabular}

AAP= Abiraterone Acetate plus prednisone ; ADT= Androgen Deprivation Therapy ; Cel= celecoxib ; Doc $=$ docetaxel ; ZA=

Zoledronic Acid 
Fig. 3 Forest plot of the effect on OS (>70 years)

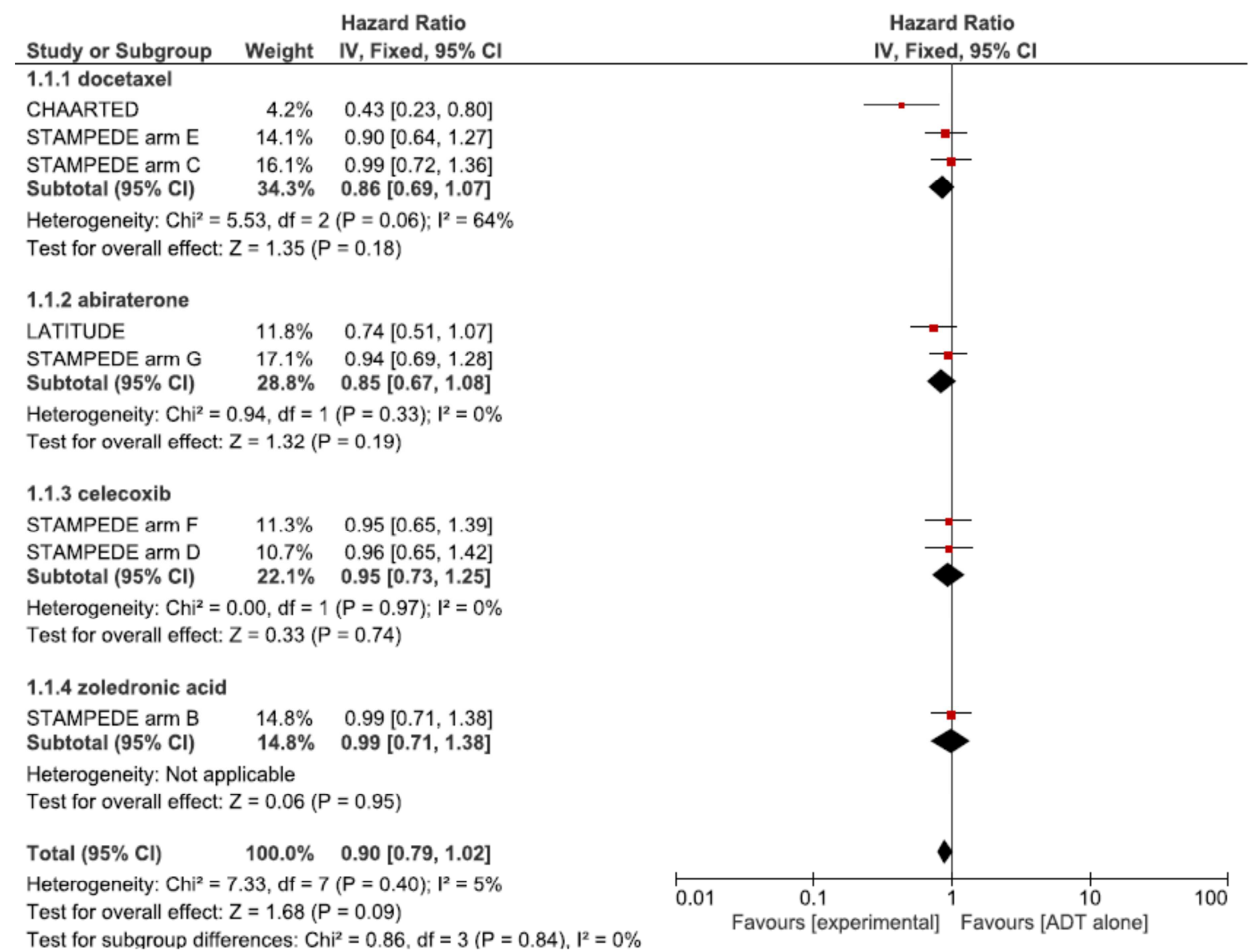


Fig. 4 Independent analysis: Forest plot of the effect on OS (>70 years)

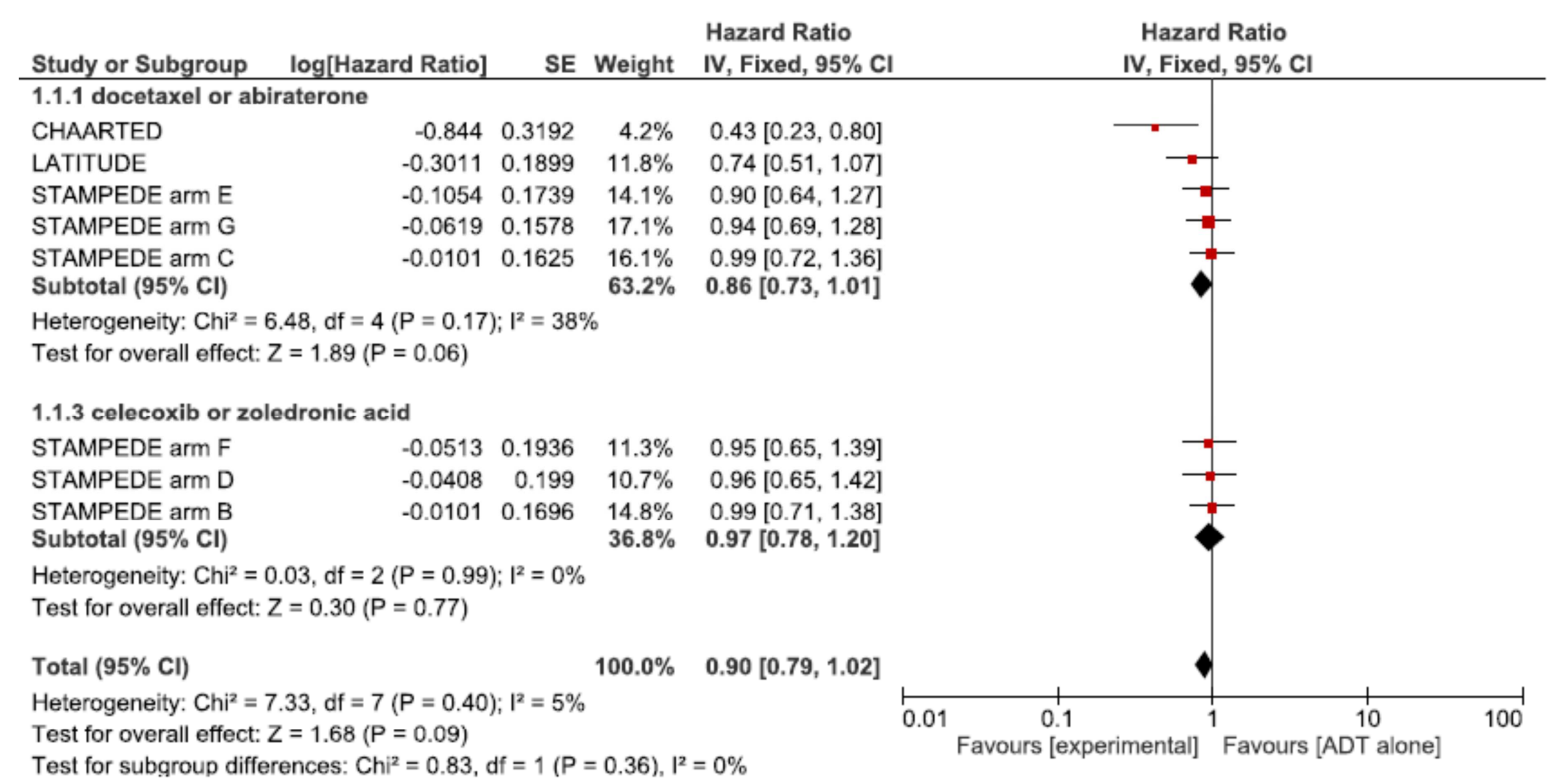


Fig.5 Forest plot of the effect on OS (<70 years)

Hazard Ratio

Hazard Ratio

Study or Subgroup Weight IV, Random, $95 \% \mathrm{Cl}$

IV, Random, $95 \%$ C

$\begin{array}{lll}\text { 1.1.1 docetaxel } & & \\ \text { CHAARTED } & 10.7 \% & 0.68[0.50,0.92] \\ \text { STAMPEDE arm E } & 13.6 \% & 0.73[0.59,0.90] \\ \text { STAMPEDE arm C } & 13.8 \% & 0.75[0.61,0.92] \\ \text { Subtotal }(95 \% \text { CI) } & 38.2 \% & 0.73[0.64,0.83]\end{array}$

Subtotal $(95 \% \mathrm{Cl}) \quad 38.2 \% \quad 0.73[0.64,0.83]$

Heterogeneity: $\mathrm{Tau}^{2}=0.00 ; \mathrm{Chi}^{2}=0.27, \mathrm{df}=2(\mathrm{P}=0.87) ; \mathrm{I}^{2}=0 \%$

Test for overall effect: $Z=4.65(P<0.00001)$

1.1.2 abiraterone

STAMPEDE arm G $\quad 12.7 \% \quad 0.51[0.40,0.65]$

LATITUDE $\quad 9.8 \% \quad 0.53[0.38,0.75]$

Subtotal $(95 \% \mathrm{Cl}) \quad 22.5 \% \quad 0.52[0.43,0.63]$

Heterogeneity: $\mathrm{Tau}^{2}=0.00 ; \mathrm{Ch}^{2}=0.05, \mathrm{df}=1(\mathrm{P}=0.83) ; \mathrm{I}^{2}=0 \%$

Test for overall effect: $Z=6.52(P<0.00001)$

1.1.3 celecoxib

STAMPEDE arm F $\quad 12.5 \% \quad 0.82[0.64,1.05]$

STAMPEDE arm D $\quad 12.9 \% \quad 1.00[0.79,1.27]$

Subtotal $(95 \% \mathrm{Cl}) \quad 25.4 \% \quad 0.91[0.75,1.10]$

Heterogeneity: Tau $^{2}=0.00 ; \mathrm{Ch}^{2}=1.29, \mathrm{df}=1(\mathrm{P}=0.26) ; \mathrm{I}^{2}=23 \%$

Test for overall effect: $Z=0.96(P=0.34)$

1.1.4 zoledronic acid

STAMPEDE arm B $\quad 13.8 \% \quad 0.91[0.74,1.12]$

Subtotal $(95 \% \mathrm{Cl}) \quad 13.8 \% \quad 0.91[0.74,1.12]$

Heterogeneity: Not applicable

Test for overall effect: $Z=0.89(P=0.37)$

Total $(95 \% \mathrm{Cl}) \quad 100.0 \% \quad 0.73[0.63,0.86]$

Heterogeneity: $\mathrm{Tau}^{2}=0.04 ; \mathrm{Chi}^{2}=23.53, \mathrm{df}=7(\mathrm{P}=0.001) ; \mathrm{I}^{2}=70 \%$

Test for overall effect: $Z=3.84(P=0.0001)$

Test for subqroup differences: $\mathrm{Ch}^{2}=20.69, \mathrm{df}=3(\mathrm{P}=0.0001), \mathrm{I}^{2}=85.5 \%$

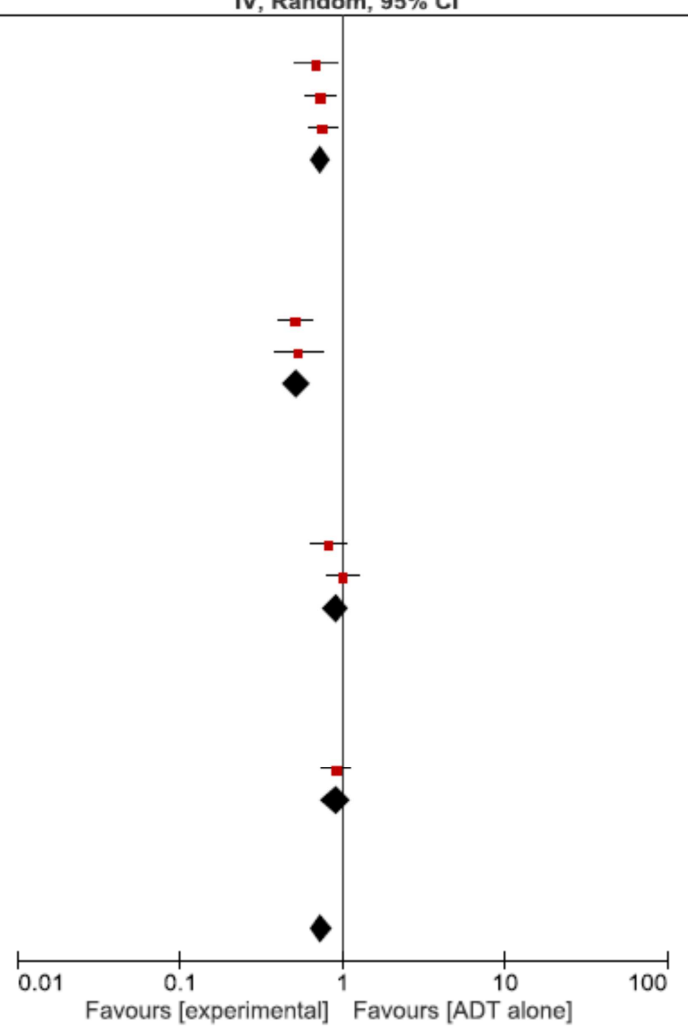


Fig. 6 Forest plot of the effect on PFS (>70 years)

Hazard Ratio

Hazard Ratio

Study or Subgroup Weight IV, Random, $95 \% \mathrm{Cl}$

IV, Random, $95 \% \mathrm{Cl}$

$\begin{array}{lll}\text { 1.1.1 docetaxel } & & \\ \text { STAMPEDE arm C } & 15.9 \% & 0.50[0.38,0.66] \\ \text { STAMPEDE arm E } & 17.2 \% & 0.51[0.40,0.65] \\ \text { Subtotal }(95 \% \mathrm{CI}) & 33.1 \% & \mathbf{0 . 5 1}[0.42,0.61]\end{array}$

Subtotal $(95 \% \mathrm{Cl})$

Heterogeneity: $\mathrm{Tau}^{2}=0.00 ; \mathrm{Chi}^{2}=0.01, \mathrm{df}=1(\mathrm{P}=0.92) ; \mathrm{I}^{2}=0 \%$

Test for overall effect: $Z=7.35(P<0.00001)$

1.1.2 abiraterone

STAMPEDE arm G $\quad 10.6 \% \quad 0.41[0.27,0.62]$

LATITUDE $\quad 12.2 \% \quad 0.55[0.38,0.80]$

Subtotal $(95 \% \mathrm{Cl}) \quad 22.7 \% \quad 0.48[0.36,0.64]$

Heterogeneity: $\mathrm{Tau}^{2}=0.00 ; \mathrm{Chi}^{2}=1.06, \mathrm{df}=1(\mathrm{P}=0.30) ; \mathrm{I}^{2}=5 \%$

Test for overall effect: $Z=4.98(P<0.00001)$

1.1.3 celecoxib

STAMPEDE arm D $\quad 13.1 \% \quad 0.55[0.39,0.78]$

STAMPEDE arm F $\quad 13.9 \% \quad 0.80[0.58,1.10]$

Subtotal $(95 \% \mathrm{Cl}) \quad 27.0 \% \quad 0.67[0.46,0.96]$

Heterogeneity: $\mathrm{Tau}^{2}=0.04 ; \mathrm{Chi}^{2}=2.43, \mathrm{df}=1(\mathrm{P}=0.12) ; \mathrm{I}^{2}=59 \%$

Test for overall effect: $Z=2.16(P=0.03)$

1.1.4 zoledronic acid

$\begin{array}{lll}\text { STAMPEDE arm B } & 17.1 \% & 0.78[0.61,1.00] \\ \text { Subtotal }(\mathbf{9 5} \% \mathrm{CI}) & \mathbf{1 7 . 1} \% & \mathbf{0 . 7 8}[\mathbf{0 . 6 1}, \mathbf{1 . 0 0}]\end{array}$

Heterogeneity: Not applicable

Test for overall effect: $Z=1.98(P=0.05)$

Total $(95 \% \mathrm{Cl}) \quad 100.0 \% \quad 0.58[0.48,0.69]$

Heterogeneity: $\mathrm{Tau}^{2}=0.03 ; \mathrm{Chi}^{2}=14.34, \mathrm{df}=6(\mathrm{P}=0.03) ; \mathrm{I}^{2}=58 \%$

Test for overall effect: $Z=5.95(P<0.00001)$

Test for subgroup differences: $\mathrm{Chi}^{2}=9.87, \mathrm{df}=3(\mathrm{P}=0.02), \mathrm{I}^{2}=69.6 \%$

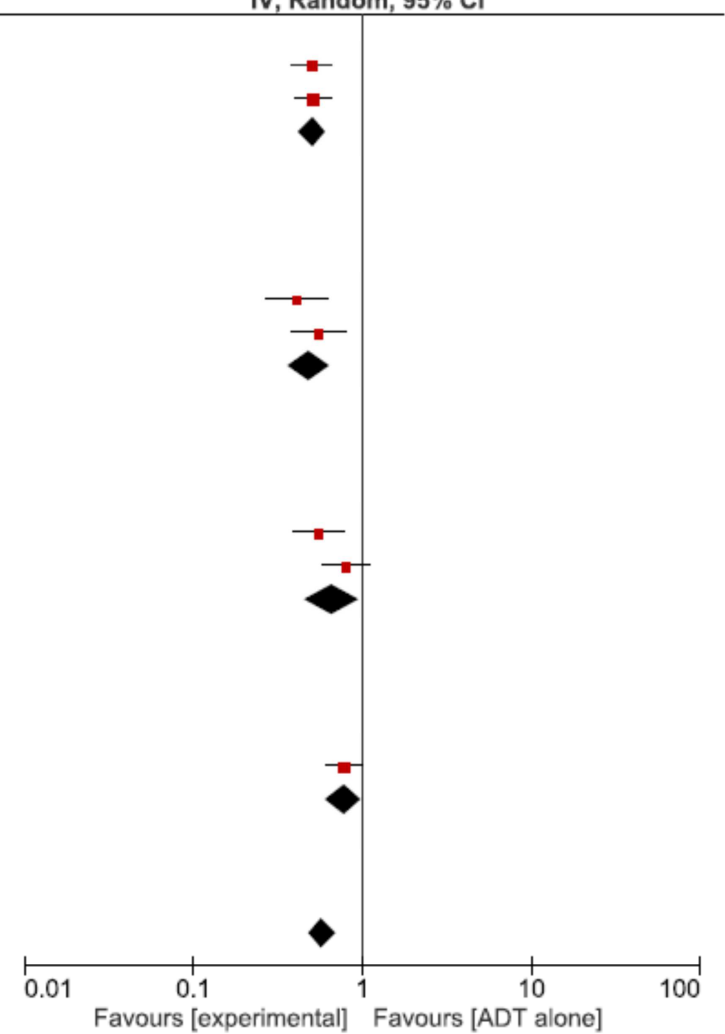

